\title{
Antifungal potential of terpenes from spondias purpurea I. leaf extract against moniliophthora perniciosa that causes witches broom disease of theobroma cacao
}

\begin{abstract}
The present in vitro study evaluates antifungal properties of Spondias purpurea plant extract against Moniliophthora perniciosa. Fractions of Ethanol Crude Extracts (CE) from $S$. purpurea were tested for their antifungal activity. CE inhibited mycelial growth of M. perniciosa by $60 \%$ at a dose of $10 \mathrm{mg} / \mathrm{mL}$, while survival of broken hyphae of the fungus was inactivated by $90 \%$ at a dose of $8 \mathrm{mg} / \mathrm{mL}$. Fractionation of CE yielded a terpene containing sub fraction (FA) with the highest fungicidal activity. FA acted as oxidant and its application induced oxidative stress in M. perniciosa that may be the responsible for the observed induced cell death. The chromatographic profile obtained with FA of $S$. purpurea revealed a variety of terpenes, which included Spathulenol (14.2\%), Linolenic acid $(8.4 \%)$, trans Caryophyllene $(6.9 \%)$, and Alpha-muurolene $(6.9 \%)$. This study describes for the first time effects of terpenes of $S$. purpurea related to induced oxidative stress in fungus. S. purpurea, therefore, may be a natural source for isolation of antifungal compounds against $M$. perniciosa. This characteristic may be useful in application as botanical fungicide in biological control.
\end{abstract}

Keywords: moniliophthora perniciosa, spondias purpurea, biofungicide, terpenes, natural products, theobroma cacao
Volume 7 Issue I - 2017

\author{
Gabriele Marisco,' Regineide Xavier Santos,' \\ Rosane Aguiar, ${ }^{2}$ Martin Brendel, ${ }^{3}$ Cristina \\ Pungartnik' \\ 'Departamento Ciências Naturais, Universidade Estadual do \\ Sudoeste da Bahia, Brazil \\ ${ }^{2}$ Departamento Química e Exatas, Universidade Estadual do \\ Sudoeste da Bahia, Brazil \\ ${ }^{3}$ Departamento Ciências Biológicas, Universidade Estadual de \\ Santa Cruz, Brazil
}

\begin{abstract}
Correspondence: Cristina Pungartnik, Departamento Ciências Biológicas, Universidade Estadual de Santa Cruz, Laboratório de Biologia dos Fungos, Rodovia Ilhéus Itabuna, Km-16, Salobrinho, Ilhéus, Bahia, Brazil, Tel +557336805438,

Email cpungartnik@yahoo.com.br
\end{abstract}

Received: February 20, 2017| Published: May 17, 2017

\section{Introduction}

Moniliophthora perniciosa (Stahel) is a hemibiotrophic phytopathogenic fungus which infects cacao (Theobroma cacao L.) and causes witches broom disease. ${ }^{1}$ It has introduced serious socioeconomic and environmental problems ${ }^{2}$ by reducing cacao production in Southern Bahia, the main cacao producing region in Brazil. ${ }^{3}$ There have been numerous efforts in the last 25years, to halt the spread or to eradicate this phytopathogenic fungus. Several strategies in minimizing $M$. perniciosa induced crop damage have emerged:

a. Increase of T. cacao plant resistance, ${ }^{4,5}$ identification of new resistant progenies of cacao accessions from the Brazilian Amazon

b. Development of new fungicides or isolation from natural sources of chemical compounds with antifungal properties ${ }^{2,6-13}$

c. Clarification by molecular studies to understand mechanisms of host-pathogen interaction ${ }^{14,15}$ and

d. Application of combination treatment with the biological control fungus Trichoderma stromaticum and the fungicide copper hydroxide. This presently appears to be the best alternative in control of M. pernicios. ${ }^{16}$

However, growth of T. cacao seed lings subjected to increasing levels of copper $(\mathrm{Cu})$ is negatively affected ${ }^{17}$ and $\mathrm{Cu}$ also is known to cause environmental problems. ${ }^{18}$ Synthetic pesticides and fungicides may have various side effects on human health, including carcinogenicity, teratogenicity and residual toxicity. ${ }^{19}$ Therefore, biological control appears to be beneficial in reducing effects of witches' broom disease to economically viable levels and in decreasing the use of chemical fungicides that may cause collateral damage. ${ }^{6}$ The chemical components occurring naturally in variety of plants in Brazilian ecosystems are a potential source of bioactive materials. ${ }^{20}$ Plant metabolites and plant-based pesticides and fungicides increasingly appear to be a promising alternative to synthetic pesticides as their application promises minimal environmental impact. ${ }^{21,22}$ Therefore, they are helpful for the development of effective products for pest control. $^{23}$ including pathogenic fungi ${ }^{24-26}$ Spondias purpurea L. (Family: Anacardiaceae), originating from the region of Mexico and Central America, ${ }^{27}$ is widely present in north eastern Brazil, ${ }^{28}$ Popularly known as Seriguela or Ciruela, it is traditionally used in the treatment of anemia, diarrhea, dysentery and skin infections. ${ }^{29}$ In Brazil it is also used against diabetes and high cholesterol. ${ }^{30,31}$ Its economic importance is also derived from the production of fruits, juices, jams, ice cream and alcoholic beverages. ${ }^{32}$

In vitro studies showed antifungal activity of $S$. purpurea as aqueous leaf extract decreased the germination of Rhizopus stolonifer conidia. ${ }^{33}$ Aqueous extracts of leaf and stem could inhibit spore formation of Colletotrichum gloeosporioides, ${ }^{34}$ while methanol leaf extract and powders inhibited the mycelial growth of Fusarium oxysporum while hexane extract decreased its sporulation. ${ }^{25}$ Based on increasing public concern about pesticide residues in food products, as well as about soil-degrading effects of fungicides, the availability of a sustainable, environmental-friendly method for disease control in T. cacao is highly desirable ${ }^{35}$ and generally, biocontrol appears to be one of the few viable approaches. ${ }^{36}$ Therefore, we aimed to evaluate in vitro the antifungal potential of $S$. purpurea extract against the plant pathogen M. perniciosa.

\section{Materials and methods}

\section{Plant extract}

The plant $S$. purpurea was collected from Vitória da Conquista, Bahia (UESB, $14^{0} 52^{\prime} 49^{\prime}$ ' S $\left.40^{\circ} 47^{\prime} 34^{\prime \prime W}\right)$. Voucher specimen were 
identified and deposited in the herbarium at UESB (number 6457). The leaves were macerated with a pistil after drying in circulating warm air at $40^{\circ} \mathrm{C}$ for 2 days. A $100 \mathrm{~g}$ powdered sample was exhaustively extracted with $99.9 \%$ ethanol. The ethanol was removed using a rotary evaporator to produce a dry powder of the Crude Extract (CE) after filtering with filter papers.

\section{Fractionation of the crude extract of S. purpurea}

Extracts with different polarities were obtained by liquid-liquid partition from the Crude Ethanol Extract of S. purpurea (CE). ${ }^{37}$ Initially $1.0 \mathrm{~g}$ of $\mathrm{CE}$ was dissolved in $\mathrm{MeOH}: \mathrm{H}_{2} \mathrm{O}(4: 1)$, then it was homogenized for $5 \mathrm{~min}$ and filtered. The resulting filtrate was acidified with $\mathrm{H}_{2} \mathrm{SO}_{4}$ and then partitioned with $\mathrm{CHCl}_{3}$. The organic phase generated the chloroform fraction (FA), while the acidic alcoholic hydro phase was basified and partitioned with $\mathrm{CHCl}_{3}$ : $\mathrm{MeOH}(3: 1)$. The organic phase, after removing the solvent, generated the basic chloroform fraction (FB), while the hydro alcoholic phase contained the basic hydro-alcoholic fraction (FC). The filtration residue was extracted with EtOAc. After solvent evaporation the fraction of EtOAc (FD) was obtained.

\section{In vitro antifungal assay}

M. perniciosa strain and growth conditions: Strain ALF553 of $M$. perniciosa (deposited at Universidade Estadual de Feira de Santana, at Feira de Santana, Bahia, Brazil, access number CCBM000257)was used in all the experiments. Starter cultures of M. perniciosa were kept for $14 \mathrm{~d}$ at $25^{\circ} \mathrm{C}$ on solid agar media (CPD: $2 \%$ glucose, $2 \%$ peptone; $2 \%$ agar used as solidifying agent). Dikaryotic phase of growth was microscopically confirmed by the presence of clamp connections while species-specificity of $M$. perniciosa cultures was confirmed by PCR amplification of the actin gene (data not shown). ${ }^{38}$

M. perniciosa sensitivity to CE: The starter culture of $M$. perniciosa containing disc $(2-3 \mathrm{~mm})$ was then transferred to CEsupplemented CPD $(1,10$ and $20 \mathrm{mg} / \mathrm{mL} \mathrm{CE})$. CE was diluted in $99.9 \%$ p.a. ethanol and the maximum ethanol concentration per agar plate was $5 \%$. Plates were incubated at $25^{\circ} \mathrm{C}$ for 14 days. The halo of $M$. perniciosa mycelial growth was photographed and measured. Photos are representative for a minimum of 3 experiments. Results are expressed as percent $\left(\mathrm{N} / \mathrm{N}_{\mathrm{o}} \times 100\right)$ of reduction of treated mycelium diameter $(\mathrm{N})$ as compared to control $\left(\mathrm{N}_{\mathrm{o}}\right)$. Data represents media and standard deviation of minimum 4 measurements per plate, (i.c. 95\%) for at least 3 plates. Ethanol-only control plates did not differ from control plates (CPD medium).

M. perniciosa survival curve to $\mathbf{C E}$ and sub fractions: Sensitivity of $M$. perniciosa broken hyphae to $\mathrm{CE}$ and its four sub fractions (FA, FB, FC, and FD) in either liquid or solid CPD was determined by the methodology described by Filho et al., ${ }^{39}$ Briefly, two to three discs $(2-3 \mathrm{~mm})$ were cut out from the periphery of the mycelium of the starter culture and transferred into $5 \mathrm{~mL}$ of liquid CPD containing $1 \mathrm{~g}$ of sterile glass beads (Sigma, G1277). After vigorous vortexing for $60 \mathrm{~s}, 1$ to $3 \mathrm{~mL}$ of the resulting suspension was transferred to $10 \mathrm{~mL}$ fresh liquid media and incubated for $7 \mathrm{~d}$ without agitation. From this liquid culture $1-3 \mathrm{~mL}$ of $M$. perniciosa suspension was again vortexed and re-suspended in $10 \mathrm{~mL}$ of liquid CPD. This suspension was used for M. perniciosa survival experiments in two different ways:

a. One $\mathrm{mL}$ of broken hyphae suspension of M. perniciosa was applied to three plates of CPD $+\mathrm{CE}$ (solid CPD containing 0,2, 4 and $8 \mathrm{mg} / \mathrm{mL}$ of $\mathrm{CE}$, respectively) and the absolute number of "colonies" was counted after incubation at $25^{\circ} \mathrm{C}$ for $7 \mathrm{~d}$. b. The suspension was incubated for $1 \mathrm{~h}$ with each of the fractions FA, FB, FC, FD in liquid CPD in different concentrations (0, $0.25,0.5,1$ and $5 \mathrm{mg} / \mathrm{mL}$ ) and was then placed on CPD agar plates. With either procedure each of the three treated plates gave rise to a number of $M$. perniciosa "colonies" that derived from the treated broken hyphae per $\mathrm{mL}$ of suspension $(\mathrm{N})$. Control plates (without $\mathrm{CE}$ or sub fractions $\left(\mathrm{N}_{\mathrm{o}}\right)$ ) yielded colonies of $M$. perniciosa at $100 \%$ survival rate. Results are given as the percentage of survival related to the untreated controls $(\mathrm{N} /$ $\mathrm{N} \times 100$ ) and represent the mean of at least three independent experiments. Survival data are presented in a semi-log graph. ${ }^{39,40}$ Standard deviation and statistical analysis was done with the Graph Pad Prism program.

\section{Phytochemical screening}

The extracts (CE, FA, FB, FC, FD) of $S$. purpurea were subjected to qualitative chemical screening for the identification of the classes of alkaloids, flavonoids, tannins, saponins, terpenes and proteins, according to methodology described. ${ }^{41,42}$

\section{Fluorescence assay}

M. perniciosa hyphae were treated with $1 \mathrm{mg} / \mathrm{mL}$ FA at $25^{\circ} \mathrm{C}$ for $1 \mathrm{~h}$. The hyphae were then washed twice with $0.9 \%$ saline. A one $\mathrm{mL}$ sample of the treated hyphae was then stained by addition of $1 \mu \mathrm{L}$ stock solution of dihydroethidium (DHE; Sigma-Aldrich) $(1 \mathrm{mg} /$ $\mathrm{mL}$ ) and mixed by inverting it. After incubation at $37^{\circ} \mathrm{C}$ for $30 \mathrm{~min}$ hyphae were washed thrice with $0.9 \%$ saline and re-suspended in $100 \mu \mathrm{L}$ of saline. One $\mathrm{mL}$ samples of non-treated and treated hyphae (with $4 \mathrm{mM} \mathrm{H}_{2} \mathrm{O}_{2}$ ) were processed under the same conditions and were checked for oxidative/reductive stress. Images were captured using a $40 \mathrm{X}$ objective under bright field as well as under fluorescent filters using IM50 software (Leica). The photographs are representative for hyphae from at least three independent experiments.

\section{Chromatographic analysis}

The chemical constituents of fraction FA were analyzed using a Shimadzu QP5050A GC-MS, fitted with Shimadzu AOC-20i auto sampler. The GC-MS with (5\%-phenyl) methylpolysiloxane DB-5 capillary column $(30 \mathrm{~m} \times 0.25 \mathrm{~mm})$ with thickness of $0.25 \mu \mathrm{m}$; carrier gas helium at $1.2 \mathrm{~mL} / \mathrm{min}$ with split less mode was used. Temperatures of the injector and detector were set at $280^{\circ} \mathrm{C}$ and $280^{\circ} \mathrm{C}$ respectively. The column temperature was programmed at $60^{\circ} \mathrm{C}$ (hold $1 \mathrm{~min}$ ) to 180 ${ }^{\circ} \mathrm{C}$ (hold $1 \mathrm{~min}$ ) at $4{ }^{\circ} \mathrm{C} / \mathrm{min}$ and then at $260^{\circ} \mathrm{C}$ (hold $25 \mathrm{~min}$ ) at $10^{\circ} \mathrm{C} /$ $\mathrm{min}$. The mass spectra were produced by electron impact at $70 \mathrm{eV}$. The constituents were identified by comparing retention indices (RI) with the corresponding reference data in $\mathrm{Adams}^{43}$ and by using the library of mass spectra of NIST11. C13 to C20 n-paraffin hydrocarbons mixture was used to obtain the RI. Also, injections of sample and standards in GC-FID, under the same conditions of analysis, were used to obtain the percentage of area.

\section{Results}

\section{Effect of S. purpurea CE on mycelial growth of $M$. perniciosa}

The results of antifungal action of the crude extract (CE) against $M$. perniciosa are shown in Figures 1A \& 1B. Radial growth of mycelia was inhibited by about $60 \%$ at $10 \mathrm{mg} / \mathrm{mL}$ and total growth inhibition by CE was achieved at $20 \mathrm{mg} / \mathrm{mL}$. 


\section{Survival of M. perniciosa hyphae treated by CE and its sub fractions}

When $M$. perniciosa hyphae were subjected to the crude extract at a dose of $8 \mathrm{mg} / \mathrm{mL}$ they showed a high sensitivity, i.e., only $10 \%$ survival of colony forming units (Figure 1C). The survival of $M$. perniciosa hyphae after treatment with the fractions (FA, FB, FC, FD) of $\mathrm{CE}$ is shown in Figure 2. FA had highest antifungal activity at $1 \mathrm{mg} /$ $\mathrm{mL}$ followed by FD at $5 \mathrm{mg} / \mathrm{mL}$ and further followed by FB. FC was not active at any concentration.

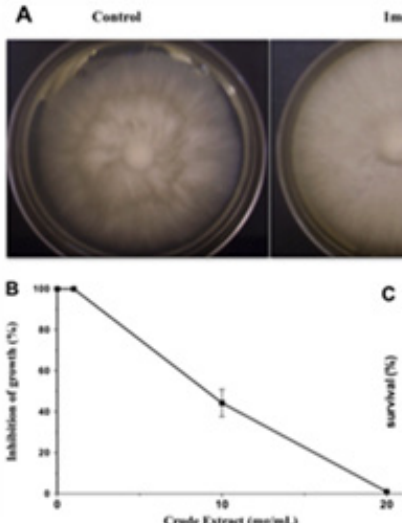

Imaint.

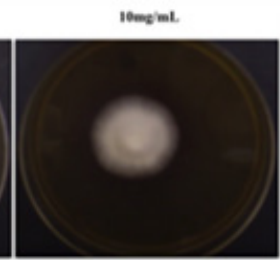

\section{${ }^{100}$}

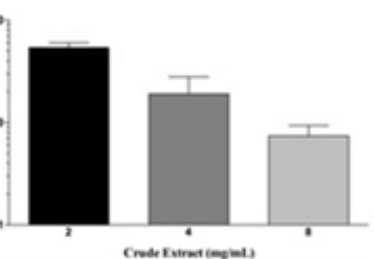

Figure I Effect on radial growth of $M$. perniciousa of different $C E$ concentrations.

A. Photo of the representative mycelia

B. Measured growth expressed as a percentage 14 days after plating

Survival of $M$. perniciosa (hyphae) submitted to solid culture medium supplemented with CE and incubated for 7 days.

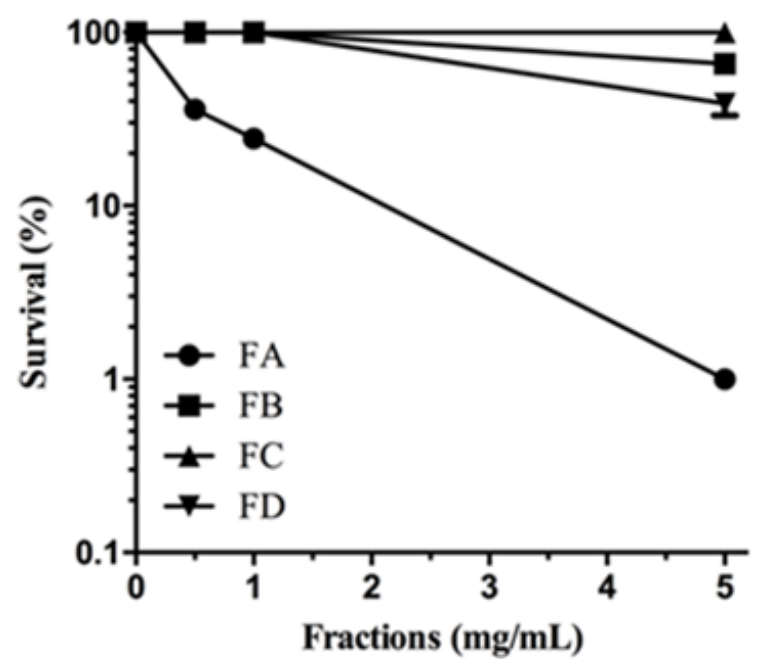

Figure 2 Sensitivity of $M$. perniciosa hyphae treated with S. purpurea CE $(0.25$, 0.5 , I and $5 \mathrm{mg} / \mathrm{mL}$ respectively) in liquid CPD media for $\mathrm{I} \mathrm{h}$ and plated on CPD medium; number of colonies were counted after $7 \mathrm{~d}$ incubation at $25^{\circ} \mathrm{C}$.

\section{Phytochemical screening}

S. purpurea $\mathrm{CE}$ and its three sub fractions exhibiting antifungal activity were phytochemically analyzed in a qualitative screening of the main secondary metabolites. Tannins were present in CE, FA and $\mathrm{FB}$, while saponins were absentin FD. Alkaloids were present in CE and FB. However, terpenes could only be detected in CE and FA.

\section{FA from S. purpurea induced oxidative stress in $M$. perniciosa}

Vegetative growth on CPD (control mycelium without FA) (Figure $3 \mathrm{~A}$ ) was compared to mycelium growth after $\mathrm{H}_{2} \mathrm{O}_{2}$ treatment $(4 \mathrm{mM}$, Figure $3 \mathrm{~B})$ and FA $(1 \mathrm{mg} / \mathrm{mL}$, Figure $3 \mathrm{C})$ on the basis of observations obtained by fluorescent microscopy. Some oxidation was observed in non-treated mycelia (Figure 3A). Oxidation produced by reactive oxygen species (ROS) after $\mathrm{H}_{2} \mathrm{O}_{2}$ treatment (Figure 3B) was clearly higher in comparison to control. Oxidation induced by FA (Figure 3C) was much stronger when compared to positive $\mathrm{H}_{2} \mathrm{O}_{2}$ treatment control (Figure 3B).

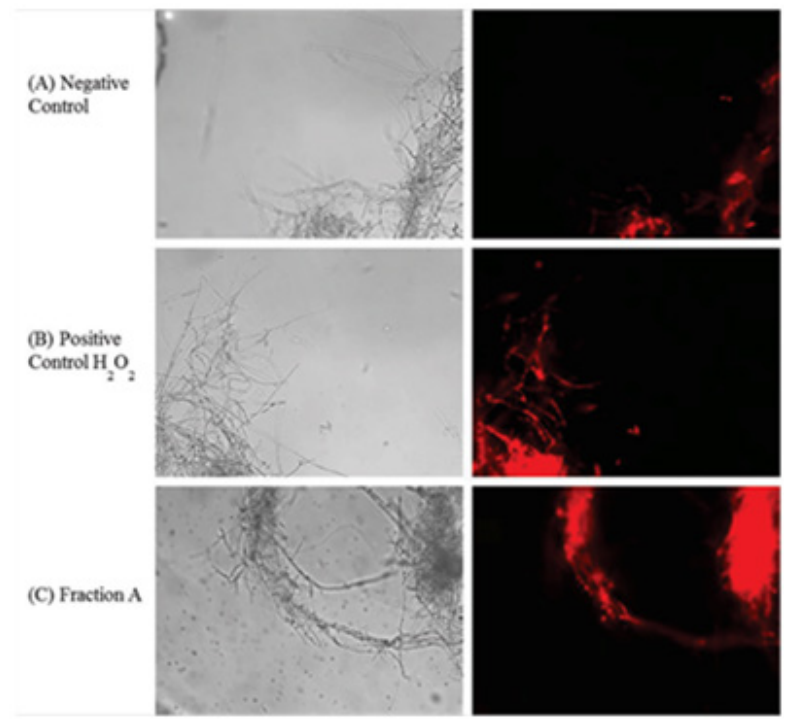

Figure 3 Visualization of oxidative stress induced by sub fraction $A$ of $S$. purpureal leaf extract via fluorescence microscopy of DHE-stained $M$. perniciosa.
A. Negative control
B. $4 \mathrm{mM} \mathrm{H} \mathrm{H}_{2}$
C. $F A(I \mathrm{mg} / \mathrm{mL})$.

\section{Chromatographic analysis}

It lists the chemical constituents of FA, the sub fraction with the highest antifungal activity, identified by GC-MS and GC-FID. The chromatographic analysis of the study identified 14 components $(78 \%$ of the sample), amongst them the presence of sesquiterpenes (56.09\%) as major constituents; spathulenol (14.2\%), trans-caryophyllene $(6.9 \%)$ and alpha-muurolene $(6.9 \%)$, in addition to free fatty acid, linolenic acid (8.4\%).

\section{Discussion}

Previous studies with aqueous extracts of $S$. purpurea leaves demonstrated the fungicidal potential on Rhizopus stolonifera ${ }^{33}$ and the aqueous extracts from leaf and stem totally inhibited the sporulation in Colletotrichum gloeosporioides. ${ }^{34}$ These results suggested further studies, e.g., to isolate and identify the compounds with fungicidal potential from the extracts. In this present study, S. purpurea $\mathrm{CE}$ totally inhibited the growth of the basidiomycete fungus $M$. perniciosa at $20 \mathrm{mg} / \mathrm{mL}$, and about $60 \%$ at $10 \mathrm{mg} / \mathrm{mL}$ when applied to solid agar media. In the first attempt of isolation of compounds responsible for M. perniciosa cytotoxicity, CE was fractionated using polarity separation methodology. ${ }^{37}$ Three of 4 fractions FA, FB, and FC of CE had antifungal activity as they were cytotoxic against $M$. 
perniciosa (Figure 2). Fraction FD displayed no antifungal activity. The differential distribution of bioactivity among the fractions might be explained by the proportions of different bioactive components of each fraction, acting either in a synergetic or in potentiating way. ${ }^{44}$ Since FA showed the strongest inhibition of mycelial growth, we chose it for further analytical studies.

Phytochemical screening of CE and fractions can be correlated with cytotoxicity to $M$. perniciosa (Figure 2). While all secondary tested metabolites could be detected in $\mathrm{CE}$ and, per definition rendered $100 \%$ of cytotoxicity, only sub fraction FA that contains only terpenes was able to induce the same cytotoxicity. Phytochemicals contained in FB and FC could also induce cytotoxicity, however to a lesser degree than to one shown for CE and FA. The effect of plant extracts on fungal pathogens may be attributed to their content of secondary metabolites (e.g., alkaloids, phenolics, flavonoids and terpenoids) with known antifungal activity. ${ }^{45,46}$ Antifungal activity of $S$. purpurea extract was associated with the concentration of sesquiterpenesas it inhibited the growth of mycelium of Fusarium oxysporum..$^{25}$ Therefore, we only submitted FA to GC-MS analysis. Major constituents of FA were sesquiterpenes $(56.09 \%)$, which could be associated with a high degree of cytotoxicity (Figure 2). Terpenes are known to induce membrane disruption of lipophilic compounds ${ }^{24}$ and are also known to induce ROS. ${ }^{47}$ Hence, a fluorescence assay with DHE was performed (Figure 3). Interaction of cytosolic DHE when oxidized by ROS (singlet oxygen, hydroxyl radicals, superoxide, peroxides and hydro peroxides) produces ethidium, which intercalates with DNA and emits bright red fluorescence at $605 \mathrm{~nm} .{ }^{48}$ Induction of oxidative stress after FA and $\mathrm{H}_{2} \mathrm{O}_{2}$ detected by DHE was observed (Figure 3). The amount of FA used in this study showed considerable higher oxidant activity, which effects mycelial growth of M. perniciosa in vitro (Figure 3C) in comparison to oxidative stress induced by $\mathrm{H}_{2} \mathrm{O}_{2}$ (Figure 3B). DHE-exposed M. perniciosa hyphae had shown a similar profile when subjected to a free radical-generating chemical treatment. Marisco et al., ${ }^{49}$ had shown similar results in the eukaryotic model in S. cerevisiae (yeast) using $\mathrm{H}_{2} \mathrm{O}_{2}$ as pro oxidant. There is evidence for the role of endogenous ROS as a causative agent in mutagenesis and as a significant contributor in the mutational burden in microbes during periods of oxidative stress in which this response may be related to Cytotoxicity. ${ }^{50}$ Thus, endogenous ROS produced by oxidative metabolism of $M$. perniciosa can explain the basal oxidant activity observed in non-treated mycelia (Figure 3A). In short, our results show that crude ethanol extract of $S$. purpurea leaves is capable of inducing cytotoxicity in M. perniciosa (Figure 1). The fraction named FA was responsible for $100 \%$ mycelia inhibition in $M$. perniciosa (Figure 2), and chemical analysis revealed sesquiterpenes as its major component. The presence of terpenes could be correlated with oxidative stress produced by $S$. purpurea FA (Figure 3), which in turn, could be responsible for the cytotoxicity in the phytopathogen M. perniciosa (Figure $1 \& 2$ ). To our knowledge, this is the first description of $S$. purpurea terpenes, the major component found in leaf extracts, to be responsible for inducing oxidative stress and the correlation with cytotoxicity on M. perniciosa. As there still little effective products against witches' broom disease in T. cacao, and chemical fungicides like copper hydroxide pose problems in soil deterioration, ${ }^{16}$ the continuing search for antifungal bio products is warranted. Leaf extracts of $S$. purpurea had significant antifungal properties, hence this plant will be a good candidate for intensified in vitro and in vivo studies of its antifungal activities. Since $S$. purpurea is widely distributed in northeastern region of Brazil and the production of leaf extract with ethanol is quite simple, this might be a good base to develop a commercially viable product for the treatment of witches' broom disease of cacao.

\section{Acknowledgements}

This work was supported by UESB and CNPq. GMS was a doctoral student in RENORBIO post-graduation program. MB was visiting professor at UESC supported by FAPESB. We thank Dr. Marco A. Costa for providing the equipment for fluorescence microscopy.

\section{Conflicts of interest}

Author declares there are no conflicts of interest.

\section{Funding}

None.

\section{References}

1. Aime MC, Phillips Mora W. The causal agents of witches' broom and frosty pod rot of cacao (chocolate, Theobroma cacao) form a new lineage of Marasmiaceae. Mycologia. 2005;97(5):1012-1022.

2. Loguercio LL, Carvalho AC, De Niella GR, et al. Selection of Trichoderma stromaticum isolates for efficient biological control of witches broom disease in cacao. Biol Control. 2009;51(1):130-139.

3. Meinhardt L, Rincones J, Bailey B, et al. Moniliophthora perniciosa, the causal agent of witches broom disease of cacao: what's new from this old foe? Mol Plant Pathol. 2008;9(5):577-588.

4. Dantas Neto A, Corrêa RX, Monteiro WR, et al. Caracterização de uma população de cacaueiro para mapeamento de genes de resistência à vassoura-de-bruxa e podridão-parda*. Fitopat Bras. 2005;30(4):380-386.

5. Paim V, Luz E, Pires J, et al. Sources of resistance to Crinipellis perniciosa in progenies of cacao accessions collected in the brazilian amazon. Sci Agricola. 2006;63(6):572-578.

6. Krauss U, Soberanis W. Biocontrol of cocoa pod diseases with mycoparasite mixtures. Biol Control. 2001;22(2):149-158.

7. Ramos A, Falcão L, Barbosa G, et al. Neem (Azadirachta indica a. Juss) components: candidates for the control of Crinipellis perniciosa and Phytophthora ssp. Microbiol Res. 2007;162(3):238-243.

8. Mejía L, Rojas E, Maynard Z, et al. Endophytic fungi as biocontrol agents of Theobroma cacao pathogens. Biol Control. 2008;46(1):4-14.

9. Cabral A, Maria P, Carvalho B, et al. Killer yeasts inhibit the growth of the phytopathogen Moniliophthora perniciosa, the causal agent of witches broom disease. Braz J Microbiol . 2009;40(1):108-110.

10. De Souza J, Bailey B, Pomella A, et al. Colonization of cacao seedlings by Trichoderma stromaticum, a mycoparasite of the witches broom pathogen, and its influence on plant growth and resistance. Biol Control. 2008;46(1):36-45.

11. Bernardi Wenzel J, Garcia A, Azevedo JL, et al. Molecular characterization by amplified ribosomal DNA restriction analysis and antimicrobial potential of endophytic fungi isolated from Luehea divaricata (Malvaceae) against plant pathogenic fungi and pathogenic bacteria. Genet Mol Res. 2013;12(4):5072-5084.

12. Flores A, Pamphile J, Sarragiotto M, et al. Production of 3-nitropropionic acid by endophytic fungus Phomopsis longicolla isolated from Trichilia elegans A. JUSS ssp. elegans and evaluation of biological activity. World J Microbiol Biotechnol. 2013;29(5):923-932.

13. Falcäo L, Silva-Werneck J, Vilarinho B, et al. Antimicrobial and plant growth-promoting properties of the cacao endophyte Bacillus subtilis ALB629. J Appl Microbiol. 2014;116(6):1584-1592.

14. Camillo LR, Filadelfo CR, Monzani PS, et al. Tc-cAPX, a cytosolic ascorbate peroxidase of Theobroma cacao L. engaged in the interaction with Moniliophthora perniciosa, the causing agent of witches' broom disease. Plant Physiol Biochem. 2013; 73:254-265. 
15. Menezes S, Silva E, Lima E, et al. The pathogenesis-related protein PR-4b from Theobroma cacao presents RNase activity, $\mathrm{Ca}^{2+}$ and $\mathrm{Mg}^{2+}$ dependent-DNase activity and antifungal action on Moniliophthora perniciosa. BMC plant biology. 2014;14:161

16. Medeiros FHV, Pomella AWV, Souza JT, et al. A novel, integrated method for management of witches broom disease in Cacao in Bahia, Brazil. Crop Prot. 2010;29(7):704-711.

17. Souza VL, Almeida AAF, Souza JDS, et al. Altered physiology, cell structure, and gene expression of Theobroma cacao seedlings subjected to Cu toxicity. Environ Sci Pollut Res Int. 2014;21(2):1217-1230.

18. Yang X, Feng Y, He Z, et al. Molecular mechanisms of heavy metal hyperaccumulation and phytoremediation. J Trace Elem Med Biol. 2005;18(4): 339-353.

19. Fathima SK, Bhat SS, Girish K. Efficacy of some essential oils against Phomopsis azadirachtae-the incitant of die-back of neem. J Biofertil Biopestic. 2009;2(2):157-160.

20. Duarte MC, Figueira GM, Sartoratto A, et al. Anti-Candida activity of Brazilian medicinal plants. J Ethnopharmacol. 2005;97(2):305-311.

21. Dubey N, Srivastava B, Kumar A. Current status of plant products as botanical pesticides in storage pest management. $J$ Biopest. 2008;1(2):182- 86 .

22. Ali A, Wee Pheng T, Mustafa M. Application of lemongrass oil in vapour phase for the effective control of anthracnose of 'Sekaki' papaya. $J \mathrm{Appl}$ Microbiol. 2015;118(6):1456-1464.

23. Marei GIK, Rasoul MAA, Abdelgaleil SAM. Comparative antifungal activities and biochemical effects of monoterpenes on plant pathogenic fungi. Pestic Biochem Physiol. 2012;103(1):56-61.

24. Cowan MM. Plant products as antimicrobial agents. Clin Microbiol Rev. 1999;12(4):564-582.

25. Pizana C, Necha L, Gómez M. Evaluation of the fungicidal activity of leaves powders and extracts of fifteen mexican plants against Fusarion oxysporum f.sp. Gadioli (Massey) Snyder and Hansen. Plant Pathol J (Faisalabad). 2010;9(3):103-111.

26. Pippi B, Lana AJD, Moraes RC, et al. In vitro evaluation of the acquisition of resistance, antifungal activity and synergism of Brazilian red propolis with antifungal drugs on Candida spp. J Appl Microbiol. 2015;118(4):83-850.

27. Leon J, Shaw PE. Spondias: the red mombin and related fruits. In: Nagy S, Shaw PE, Wardonski FW. 1990. P.117-126.

28. Ceva-antunes PMN, Ribeiro H, Silva AS, et al.Analysis of volatile composition of siriguela (Spondias purpurea L.) by solid phase microextraction (SPME). LWT. 2006;39(4):436-442.

29. Engels C, Gräter D, Esquivel P, et al. Characterization of phenolic compounds in jocote (Spondias purpurea L) peels by ultra highperformance liquid chromatography/electrospray ionization mass spectrometry. FRIN. 2012;46(2):557-562.

30. Freitas AVL, Coelho MFB, Maia SSS, et al.Plantas medicinais: um estudo etnobotânico nos quintais do Sítio Cruz, São Miguel, Rio Grande do Norte, Brasil. Revista Brasileira de Biociencias. 2012;10(1):48-59.

31. Da Siva NCB, Delfino AC, Esquibel MA, et al. Uso de plantas medicinais na comunidade quilombola da Barra II Bahia, Brasil. Boletín Latinoamericano y del Caribe de Plantas Medicinales y Aromáticas. 2012;11(5):435-453.

32. Koziol M, Macía M. Chemical composition, nutritional evaluation, and economic prospects of Spondias purpurea (Anacardiaceae). Econ Bot. 1998;52(4):373-380.
33. Bautista-Baños S, Hernández-López M, Díaz-Pérez JC, et al. Evaluation of the fungicidal properties of plant extracts to reduce Rhizopus stolonifer of "ciruela "fruit (Spondias purpurea L) During storage. Postharvest Biol Technol. 2000;20(1):99-106.

34. Bautista-Baños S, Leticia L, Necha B, et al. Antifungal Activity of Leaf and Stem Extracts from Various Plant Species on the Incidence of Colletotrichum gloeosporioides of Papaya and Mango Fruit After Storage. Rev Mex Fitopatol. 2002;20(1):8-12.

35. Hanada RE, Pomella AWV, Soberanis W, et al. Biocontrol potential of Trichoderma martial against the black-pod disease (Phytophthorapalmivora) of cacao. Biol Control. 2009;50(2):143-149.

36. Krauss U, Martijn G, Hidalgo E, et al. The effect of cane molasses amendment on biocontrol of frosty pod rot (Moniliophthora roreri) and black pod (Phytophthora spp.) of cocoa (Theobromacacao) in Panama. Biol Control. 2006;39(2):232-239.

37. Harbone JB. Phytochemical methods: A guide to modern techniques of plant analysis. Chapman and Hall, London, UK. 1984;pp:278.

38. Melo SC, Pungartnik C, Cascardo JC, et al. Rapid and efficient protocol for DNA extraction and molecular identification of the basidiomycete Crinipellis perniciosa. Genet Mol Res. 2006;5(4):851-855.

39. Filho D, PungartnikC, Cascardo J, et al. Broken hyphae of the basidiomycete Crinipellis perniciosa allow quantitative assay of toxicity. Curr Microbiol. 2006;52(5):407-412.

40. Brendel M, Haynes RH. Interactions among genes controlling sensitivity to radiation and alkylation in yeast. Mol Gen Genet. 1973;125(3):197-216.

41. Harborne J. Phytochemical Methods. $1^{\text {st }}$ edn. USA: Clarendon, Oxford; 1998.

42. Raaman N. Phytochemical Techniques. Pitam Pura, New Delhi, India. 2006.

43. Adams RP. Identification of essential oil components by gas chromatography/Mass Spectrometry. $4^{\text {th }}$ edn. Allured Publishing Corporation, Illinois, USA. 2007. p. 804.

44. Ngouana V, Fokou P, Foudjo B, et al. Antifungal activity and acute toxicity of stem bark extracts of Drypetes gossweileris. Mooreeuphorbiaceae from Camerron. Afri J Tradit Complement Altern Med. 2011;8(3):328-333.

45. Mohamed NH, El-hadidy AM Studies of biologically active constituents of Verbascum eremobium Murb. and its inducing resistance against some diseases of Cucumber. Egypt J Phytopathol. 2008;36(1-2):133-150.

46. Khaledi N, Taheri P, Tarighi S. Antifungal activity of various essential oils against Rhizoctonia solani and Macrophomina phaseolina as major bean pathogens. J Appl Microbiol. 2015;118(3):704-717.

47. Bakkali F, Idaomar M, Averbeck S, et al. Biological effects of essential oils-A review. Food Chem Toxicol. 2008;46(2):446-475.

48. Bradner JR, Nevalainen KMH. Metabolic activity in filamentous fungi can be analysed by flow cytometry. J Microbiol Methods. 2003;54(2):193-201.

49. Marisco G, Saito ST, Ganda IS, et al. Low ergosterol content in yeast adh1 mutant enhances chitin maldistribution and sensitivity to paraquatinduced oxidative stress. Yeast. 2011;28(5):363-373.

50. Dwyer DJ, Kohanski MA, Collins JJ. Role of reactive oxygen species in antibiotic action and resistance. Curr Opin Microbial. 2009;12(5):482-489. 